Research Paper

\title{
Activin B Regulates Adhesion, Invasiveness, and Migratory Activities in Oral Cancer: a Potential Biomarker for Metastasis
}

\author{
Akihiro Kita ${ }^{1}$, Atsushi Kasamatsu ${ }^{2 \varpi}$, Dai Nakashima ${ }^{1}$, Yosuke Endo-Sakamoto², Sho Ishida1, Toshihiro \\ Shimizu ${ }^{4}$, Yasushi Kimura ${ }^{5}$ Isao Miyamoto ${ }^{6}$, Shusaku Yoshimura ${ }^{1}$, Masashi Shiiba ${ }^{3}$, Hideki Tanzawa ${ }^{1,2}$, \\ and Katsuhiro Uzawa ${ }^{1,2 \bowtie}$ \\ 1. Department of Oral Science, Graduate School of Medicine, Chiba University, 1-8-1 Inohana, Chuo-ku, Chiba 260-8670, Japan \\ 2. Department of Dentistry and Oral-Maxillofacial Surgery, Chiba University Hospital, 1-8-1 Inohana, Chuo-ku, Chiba 260-8670, Japan \\ 3. Department of Medical Oncology, Graduate School of Medicine, Chiba University, 1-8-1 Inohana, Chuo-ku, Chiba 260-8670, Japan \\ 4. Department of Dentistry and Oral-Maxillofacial Surgery, Kashima Rosai Hospital, 1-9108-2 Doaihoncho, Kamisu, Ibaraki 314-0343, Japan \\ 5. Department of Dentistry and Oral-Maxillofacial Surgery, National Defense Medical College, 3-2 Namiki, Tokorozawa, Saitama 359-8513, Japan. \\ 6. Department of Dentistry and Oral-Maxillofacial Surgery, Japanese Red Cross Fukaya Hospital, 5-6-1 Kamishibachonishi, Fukaya, Saitama, 366-0052 Japan \\ $\triangle$ Corresponding author: Atsushi Kasamatsu and Katsuhiro Uzawa, Department of Oral Science, Graduate School of Medicine, Chiba University, 1-8-1 \\ Inohana, Chuo-ku, Chiba 260-8670, Japan. Tel/Fax: +81-43-226-2300; E-mail: kasamatsua@faculty.chiba-u.jp or uzawak@faculty.chiba-u.jp. \\ (C) Ivyspring International Publisher. This is an open access article distributed under the terms of the Creative Commons Attribution (CC BY-NC) license \\ (https://creativecommons.org/licenses/by-nc/4.0/). See http://ivyspring.com/terms for full terms and conditions.
}

Received: 2016.12.12; Accepted: 2017.04.08; Published: 2017.07.05

\begin{abstract}
Activin $\mathrm{B}$, a homodimer of inhibin beta $\mathrm{b}$ (INHBB), is a multifunctional cytokine belonging to the transforming growth factor- $B$ (TGF- $B$ ) family. However, the molecular functions and clinical relevance of activin $B$ have not been determined in oral cancer. We investigated the critical roles of activin $B$ in oral squamous cell carcinoma (OSCC). We performed quantitative reverse transcriptase-polymerase chain reaction, Western blotting, and immunohistochemistry to study INHBB expression in OSCC-derived cell lines and OSCC clinical samples. The INHBB expression levels were significantly $(P<0.05)$ overexpressed in OSCCs compared to normal counterparts in vitro and in vivo. Activin $\mathrm{B}$-positivity in OSCC cases was significantly $(\mathrm{P}<0.05)$ correlated with regional lymph node metastasis. The INHBB knockdown (shINHBB) cells promoted cellular adhesion and suppression of cellular invasiveness and migration. After treatment of shINHBB cells with activin B, those activities were restored similar to the shMock cells. In the processes of invasiveness and metastasis, the cells cause epithelial-mesenchymal transition (EMT). TGF- 6 and its family members are promoters of the EMT process. To investigate whether activin $B$ is related to EMT, we examined the expressions of EMT-related genes and found that INHBB was related closely to EMT. Our results suggested for the first time that activin $B$ indicates tumoral metastasis in OSCCs and might be a useful biomarker for OSCC metastasis.
\end{abstract}

Key words: activin B, inhibin beta b, INHBB, oral squamous cell carcinoma, metastasis.

\section{Introduction}

Oral squamous cell carcinoma (OSCC) is characterized by a high rate of local invasiveness and regional lymph node metastasis [1, 2]. Metastasis of cancer cells is an important factor in mortality. To improve patient prognosis, it is important to elucidate the molecular mechanism of metastasis in OSCC $[3$, 4].

Activins, a transforming growth factor- $\beta$ (TGF- $\beta$ ) family, are homo- or heterodimers of inhibin $\beta$ subunits (INH $\beta A$, INH $\beta B$ ). Their isoforms are activin $A(\beta A-\beta A)$, activin $B(\beta B-\beta B)$, and activin $A B(\beta A-\beta B)$. Activins are widely distributed in tissue and have various biologic activities, i.e., cellular proliferation, angiogenesis, inflammation, and embryogenesis [5-9].

Among the isoforms of activin, activin $\mathrm{A}$ has been reported widely in ovarian, prostate, and breast 
cancers [10-13]; however, there are a few reports of activin B in cancer research. Although exogenous activin B promotes cellular adhesion, migration, and invasiveness activities in endometrial cancer cells [14, 15], the detailed functions of activin B in OSCCs have not been reported.

The current study found for the first time that activin B is correlated closely with regional lymph node metastasis in OSCCs. Our results indicated that activin $\mathrm{B}$ might be a potential therapeutic target for patients with OSCC.

\section{Materials and Methods}

\section{Ethical statement}

The Ethics Committee of the Graduate School of Medicine, Chiba University approved this study (protocol number, 236), which was conducted according to the tenets of the Declaration of Helsinki. Before participating in our study, all patients provided informed consent.

\section{Human OSCC cell lines and tissue specimens}

Nine human OSCC cell lines, HSC-2 (RBRC-RCB1945, mouth), HSC-3 (JCRB-0623, tongue), HSC-4 (RBRC-RCB1902, tongue), Sa3 (RBRC-RCB0980, upper gingiva), Ca9-22 (RCB-1976, gingiva), SAS (RBRC-RCB 1974, tongue), KOSC-2 (JCRB-0126.1, mouth floor), Ho-1-u-1(RBRC-RCB2102, mouth floor), and Ho-1-N-1 (JCRB-0831, buccal mucosa), were purchased from the JCRB Cell Bank (Ibaraki, Osaka, Japan) and the RIKEN BioResource Center (Tsukuba, Ibaraki, Japan). We obtained human normal oral keratinocytes (HNOKs), which served as control tissue, from young healthy patients [16-23]. Clinical OSCC samples from 103 patients and normal oral mucosa (patient-matched) were obtained at the Department of Dentistry and Oral-Maxillofacial Surgery, Chiba University Hospital. Tissue samples were formalin-fixed for pathological diagnosis and immunohistochemistry (IHC). The clinical stages of the OSCCs were determined based on the TNM classification of the International Union against Cancer.

\section{mRNA expression analysis}

mRNA and cDNA synthesis extractions were conducted as previously described [23- 25]. Quantitative reverse transcriptase-polymerase chain reaction (qRT-PCR) was performed to evaluate target expression, the protocol of which was previously described [23-25]. The primer sequences were as follows: inhibin beta $b$ (INHBB), 5'-ATCAGCTTC GCCGAGACA-3' (forward) and 5'-GGTTGCCTTCG TTGGAGAT-3' (reverse); and glyceraldehyde-3- phosphate dehydrogenase (GAPDH), 5'-AACATCATCC CTGCCTCTACTGG-3' (forward) and 5'-TTGAAGTC AGAGGAGACCACTG-3' (reverse).

\section{Western blotting}

Protein extraction and Western blotting were conducted as previously described [19, 21, 22]. The antibodies used were affinity-purified rabbit anti-INHBB polyclonal antibody (Abcam, Cambridge, UK), mouse anti-GAPDH polyclonal antibody (Santa Cruz Biotechnology, Inc., Santa Cruz, CA, USA), rabbit anti-E-cadherin monoclonal antibody (Cell Signaling Technology, Danvers, MA, USA), and rabbit anti-Zonula occludens-1 (Zo-1) monoclonal antibody and rabbit anti-snail family transcriptional repressor 1 (Snail) monoclonal antibody (Cell Signaling Technology).

\section{Immunohistochemistry}

The immunohistochemistry IHC scoring system was used to quantify INHBB protein expression in OSCC clinical samples. IHC and IHC scoring systems were performed as previously described [16, 24-26]. The imaging software IHC Profiler (https://sourceforge.net/projects/ihcprofiler/) was used. The INHBB IHC scores were calculated by combining the proportion of the INHBB stained cells and the staining intensity. The intensity levels of the stained cells were classified on a scale of 0 to 3 , with 0 indicating negative, 1 low positive, 2 positive, and 3 high positive. To determine the cutoff points of the INHBB IHC scores for each clinical classification, we analyzed all scores of the 103 patients with OSCC using receiver operating characteristic (ROC) curve analysis.

\section{Transfection with shRNA plasmid}

Transfection with shRNA plasmid was conducted as previously described [27-29]. INHBB shRNA (shINHBB) and control shRNA (Mock) vectors (Santa Cruz Biotechnology, Inc.) were transfected into SAS and KOSC-2 cells.

\section{Cellular adhesion assay}

The adhesion assay was performed as previously described to assess the cellular adhesiveness with shINHBB cell and Mock cells [30]. The numbers of stained adherent cells were observed and counted using the Infinite M200 reader (Tecan, Zürich, Switzerland).

\section{Cellular invasiveness assay}

To examine the effect of INHBB knockdown on cellular invasiveness, the cells $(2.5 \times 105)$ were seeded

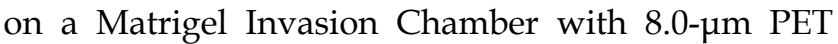
Membrane 6 Well Plates (Corning, NY, USA). The 
cellular invasiveness assay was performed as described previously [30].

\section{Cellular migration assay}

To investigate the effect of INHBB knockdown on cellular migration, the cells were plated in 6-well culture plates in Dulbecco's Modified Eagle Medium (DMEM) containing 10\% fetal bovine serum (FBS) and cultured until confluency was reached. The cellular migration assay was performed as previously described [27, 31].

\section{Cellular proliferation assay}

Cellular proliferation was measured by counting the viable cells using CellTiter 96 Aqueous AQueous One Solution Assay (Promega, Madison, WI, USA) using a colorimetric method. Cells $\left(2 \times 10^{3}\right.$ cells/well $)$ were cultured in 96-well plates with DMEM containing $10 \%$ FBS for 24 hours; the MTS reagent (3-(4,5-dimethylthiazol-2-yl)-5-(3-carboxymethoxyphe nyl)-2-(4-sulfophenyl)-2H-tetrazolium) was added directly to the cells adhering to the plate. The cells were cultured for 2 hours at $37^{\circ} \mathrm{C}$ and then measured using the Infinite M200 reader at 490-nm absorbance.

\section{Activin B treatments}

To elucidate the effect of activin $B$, the cells were treated with $50 \mathrm{ng} / \mathrm{ml}$ recombinant human activin $B$ protein (R\&D Systems, Minneapolis, MN, USA). After incubation for 24 hours, functional assays were performed.

\section{Immunofluorescence analysis}

Immunofluorescence was performed with the PathScan EMT Duplex IF Kit Primary Antibody Cocktail (Cell Signaling Technology), according to the manufacturer's instructions with minor modifications $[28,32]$. Immunofluorescence analysis was performed using confocal microscopy and analyzed with the FluoView Software (Olympus Optical, Tokyo, Japan).

\section{Statistical analysis}

Statistical significance was evaluated using the Mann-Whitney U-test, $\chi^{2}$ test, Fisher's exact test, and Student's t-test. The significance level for two-sided $P$ values was 0.05 for all tests. The data are expressed as the mean \pm standard error of the mean (SEM). We also used ROC curves to determine the optimal cutoff points to determine INHBB positivity of the OSCCs or INHBB negativity of the OSCCs in the classified clinical parameters.

\section{Results}

\section{Up-regulation of INHBB in OSCC cells}

INHBB mRNA and protein levels were up-regulated significantly $(\mathrm{P}<0.05)$ in all OSCC-derived cell lines compared with the HNOKs. Both analyses showed that the INHBB expression levels increased significantly $(\mathrm{P}<0.05)$ in all OSCC cell lines compared with the HNOKs (Fig. 1A, B).
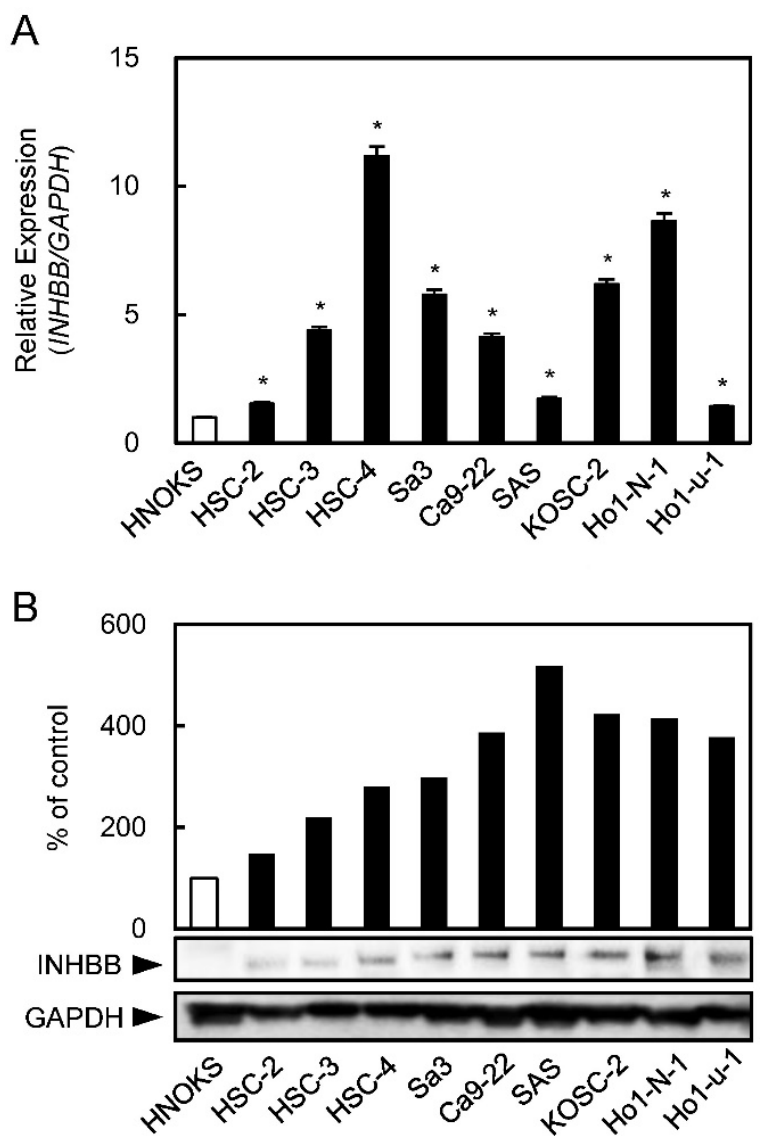

Figure 1. Up-regulation of INHBB expression in OSCC-derived cell lines. (A) Quantitation of INHBB mRNA expression by qRT-PCR analysis in OSCC-derived cell lines. Significant ( $* \mathrm{P}<0.05$, Student's t-test) up-regulation of INHBB mRNA is observed in nine OSCC-derived cell lines compared to the HNOKs. The data are expressed as the mean \pm SEM of triplicate results. (B) Western blotting of INHBB protein in OSCC-derived cell lines and HNOKs. INHBB protein expression is up-regulated in OSCC-derived cell lines compared with that in the HNOKs. Densitometric INHBB protein data are normalized to the GAPDH protein levels. The values are expressed as a percentage of the HNOKs.

\section{Evaluation of INHBB expression in primary OSCCs}

Representative IHC data from activin B in adjacent normal oral tissue and primary OSCC tissue are shown in Fig. 2A and B. The IHC scoring system showed that activin B expression was predominantly up-regulated in the cytosol of the OSCC tissue. However, almost negative immunostaining was seen in normal tissues. The activin B IHC scores in normal oral tissues ranged from 26.0 to 80.0 (median, 55.1) and in the OSCCs from 71.0 to 209.0 (median, 126.1). Activin B IHC scores in OSCCs were significantly (P < 0.05 ) greater than in normal oral tissues (Fig. $2 \mathrm{C}$ ). The 
area under the curve of the ROC curve analysis was $0.71(71 \%)$, and the cutoff value was 101.3 in the analysis of the regional lymph node metastasis (Fig. 2D).
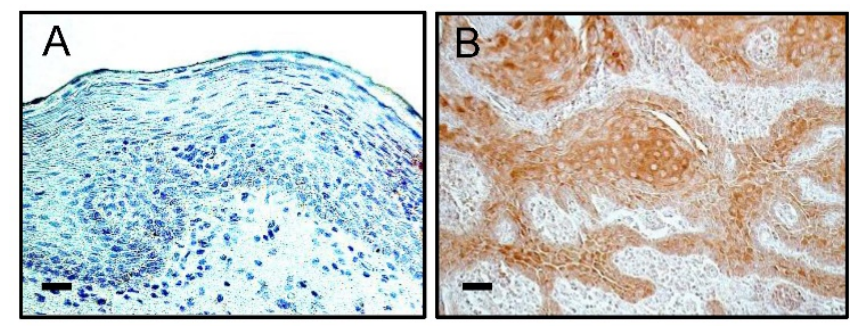

C

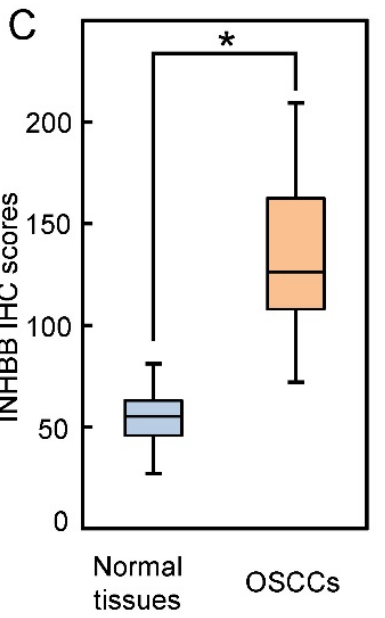

$\mathrm{D}$

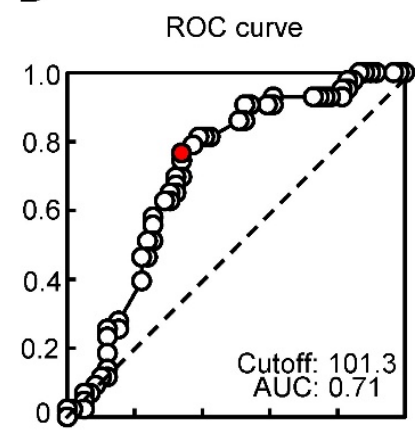

Figure 2. Evaluation of INHBB expression in primary OSCCs. Representative $\mathrm{IHC}$ results of activin $B$ in normal oral tissues (A) and primary OSCCs (B). Original magnification, $\times 200$. Scale bars, $50 \mu \mathrm{m}$. (C) The status of activin $B$ protein expression in primary OSCCs $(n=103)$ and normal counterparts. Activin B IHC scores for normal oral tissues and OSCCs range from 26.0 to 80.0 (median, 55.1) and 71.0 to 209.0 (median, 126.1), respectively. Activin B protein expression levels in OSCCs are significantly higher than in normal oral tissues ( $* P<0.05$, Student's t-test). (D) The area under the curve (AUC) of the ROC curve analysis is 0.71 , and the cutoff value is 101.3 for the regional lymph node metastasis $(P<0.05)$.

\section{Establishment of INHBB knockdown cells}

qRT-PCR and Western blotting were conducted to investigate INHBB expression levels in shINHBB cells (Fig. 3A, B, respectively). Both analyses showed that INHBB expression was down-regulated markedly $(\mathrm{P}<0.05)$ in shINHBB cells compared with Mock cells (Fig. 3A, 3B).

\section{Functional assays}

To determine the biologic effect of INHBB, we examined cellular adhesion, invasiveness, migration, and proliferation assays in the shINHBB cells (Figs. 4 and 5). Regarding adhesion assay, the numbers of shINHBB cells increased significantly $(P<0.05)$ compared with the Mock cells (Fig. 4A). Moreover, the shINHBB cells exhibited significantly $(\mathrm{P}<0.05)$ decreased cellular invasiveness and migration compared with Mock cells (Fig. 4B, C). We also examined the adhesion activity of INHBB knockdown cells with activin $B$. The adhesion activity in the shINHBB cells treated with activin B was inhibited dramatically (Fig. 5A). After treatment with activin B, the cellular invasiveness and migration of shINHBB cells were significantly $(\mathrm{P}<0.05)$ activated compared with the untreated cells (Fig. 5B, C). These results suggested that activin $B$ might directly control cellular adhesiveness and invasiveness.

A

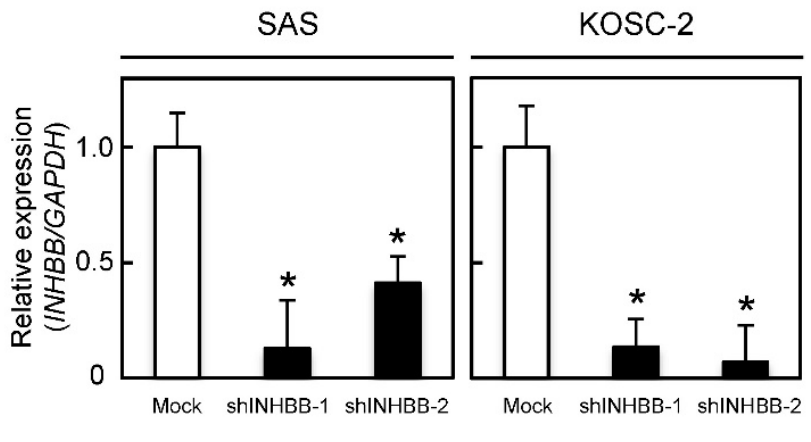

B
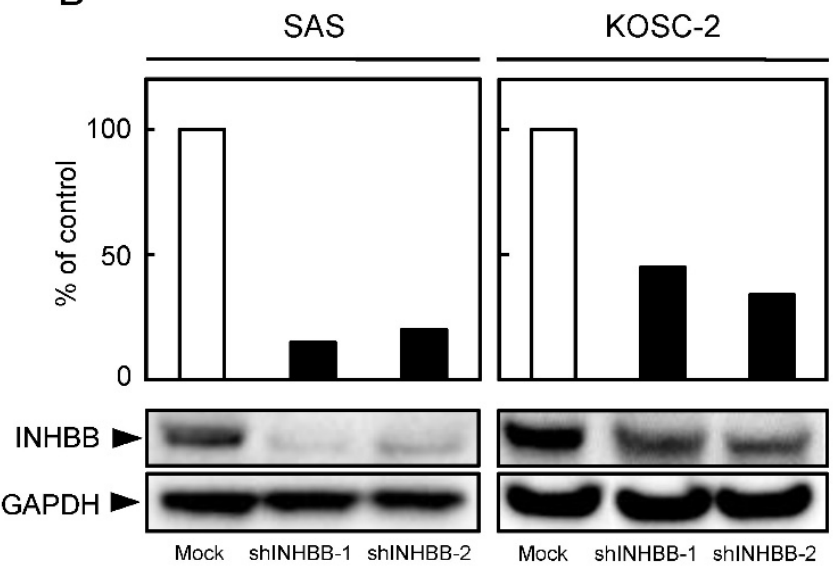

Figure 3. Establishment of INHBB knockdown cells. (A) INHBB mRNA levels in shINHBB-transfected cells. qRT-PCR shows that INHBB is down-regulated significantly (*P $<0.05$, Student's t-test) in shINHBB cells compared with Mock cells. (B) Representative Western blotting and densitometric data of INHBB protein levels in shINHBB cells and Mock cells. The INHBB protein is decreased markedly ( $* \mathrm{P}<0.05$, Student's t-test) in shINHBB-transfected cells compared with Mock cells. Densitometric INHBB protein data are normalized to GAPDH protein levels.

A cellular viability assay performed to evaluate the effect of shINHBB cells and activin B on cellular growth, however, showed that the shINHBB cells and activin B-treated shINHBB cells had similar growth curves. Therefore, these data indicated that cellular proliferation was unaffected by either cell compared with the Mock cells (Fig. 5D).

\section{EMT in INHBB knockdown cells}

Metastasis of cancer cells is the most important factor that makes treatment difficult $[33,34]$. During 
metastasis, EMT is involved in the acquisition by cancer cells of metastatic and invasive abilities [35-37]. TGF- $\beta$ and its family members promote EMT [38], which is a transformation characterized by disappearance of epithelial markers and up-regulation of mesenchymal markers [39]. No study has reported that activin B controls EMT-related

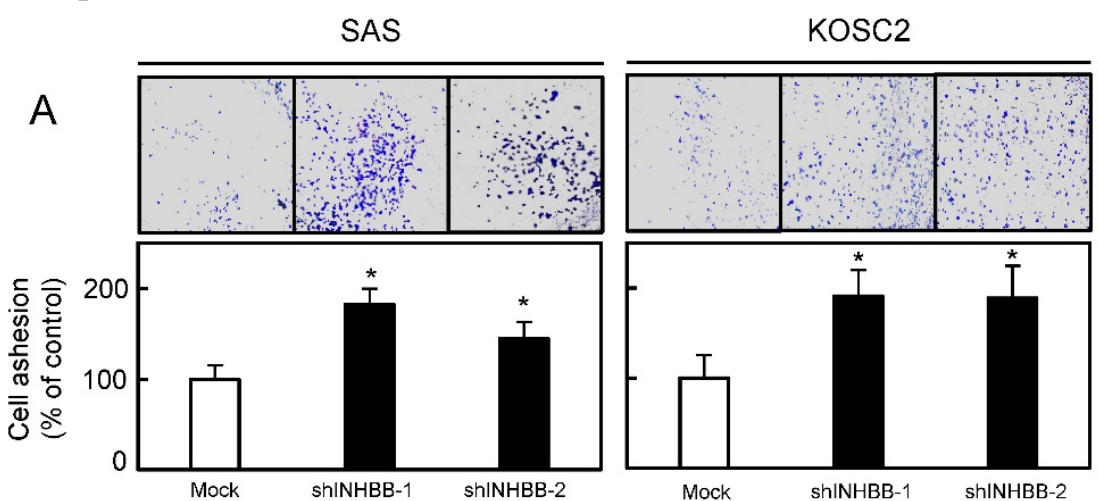

B
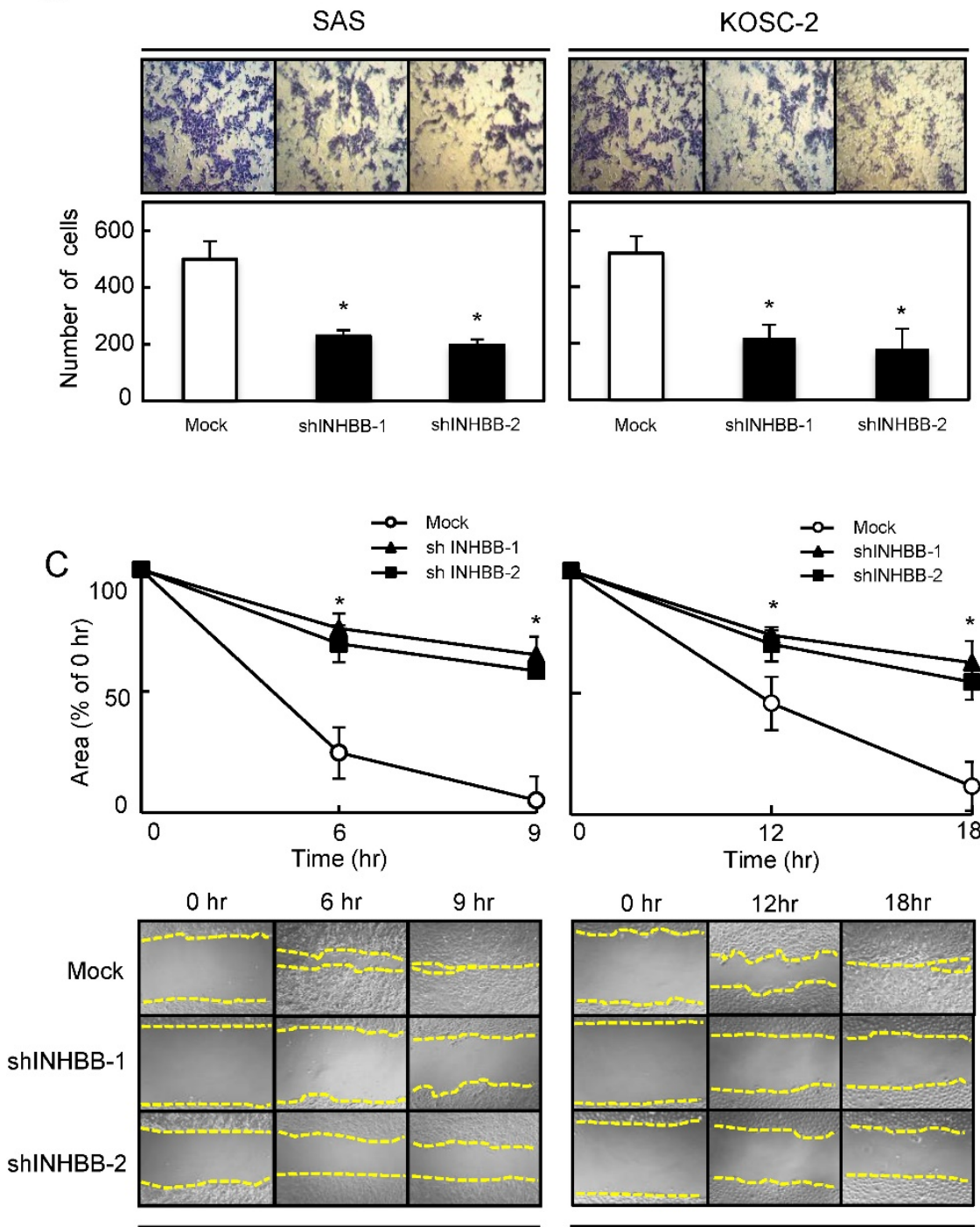

SAS genes in OSCC. To investigate the effect of activin B on EMT-related genes, expression levels and localization were observed by Western blotting and immunofluorescence. After treatment with activin B, E-cadherin and Zo-1 protein expression of shINHBB cells in SAS cells were down-regulated compared to untreated cells. Furthermore, the protein expression levels of the mesenchymal markers of EMT including Snail were up-regulated (Fig. 6A). Brightfield and immunofluorescence images of shINHBB cells were treated with/without activin B. The shINHBB cells treated with activin $B$ lost E-cadherin on the cell membrane seen by immunofluorescence (Fig. 6B). These results suggested that activin $B$, which promotes cellular adhesion and invasiveness, undergoes EMT.

Figure 4. Functional assays. (A) Adhesion assay of Mock and shINHBB cells (SAS and KOSC-2-derived transfectants). To evaluate the adhesion ability of shINHBB, the cells are seeded on collagen I-coated 96 -well plates at a density of $2 \times 10^{4}$ cells/well and allowed to adhere for 1 hour. After crystal violet staining, the numbers of stained cells are measured using a microplate spectrophotometer (absorbance at $540 \mathrm{~nm}$ and at $405 \mathrm{~nm}$ to subtract background). The cellular adhesion of the shINHBB cells are increased significantly $(P<0.05)$ compared with the Mock cells. The results are expressed as the means \pm SEM of values from three assays $(* P<0.05$, Student's t-test). (B) Invasiveness assay of Mock and shINHBB cells (SAS and KOSC-2-derived transfectants). To evaluate the effect of INHBB knockdown on invasiveness, the cells are seeded on Matrigel-coated Transwell inserts ( $8 \mu \mathrm{m}$ pores) at a density of $2.5 \times 10^{5}$ cells/well in serum-free medium. Serum-supplemented medium was added in the lower chamber as a chemoattractant. After incubation at $37^{\circ} \mathrm{C}$ for 48 hours, cells that penetrated through the pores are fixed, stained, and counted using a light microscope at $\times 100$ magnification. The number of shINHBB cells penetrating through the pores is decreased significantly $(* \mathrm{P}<0.05$, Student's t-test) compared with the Mock cells. The mean value is calculated from data obtained from three separate chambers. (C) Migration assay of Mock and shINHBB cells (SAS and KOSC-2-derived transfectants). To evaluate the effect of INHBB knockdown on migration, uniform wounds are made in confluent cultures of the shINHBB and Mock cells and the extent of closure is monitored visually every 3 hours for 18 hours. The mean value is calculated from data obtained from three separate chambers. The wound area is decreased significantly (*P $<0.05$, Student's t-test) in the Mock cell culture after 9 or 12 hours, whereas a gap remains in the shINHBB cells. 

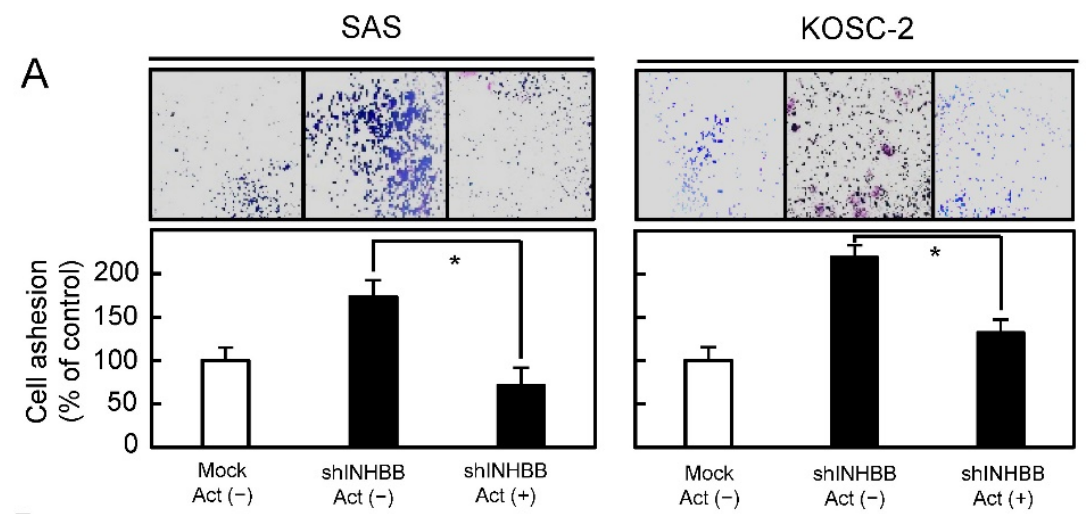

B

SAS

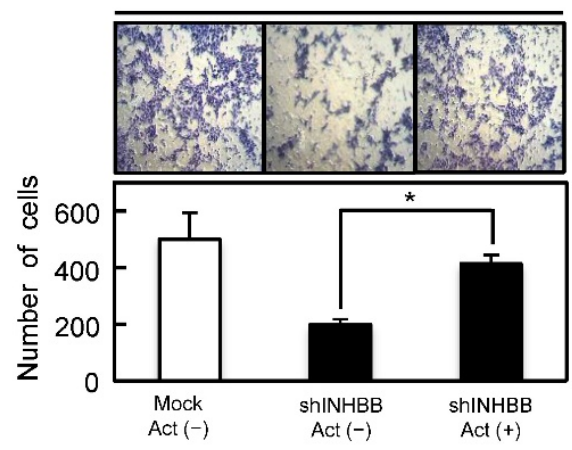

C
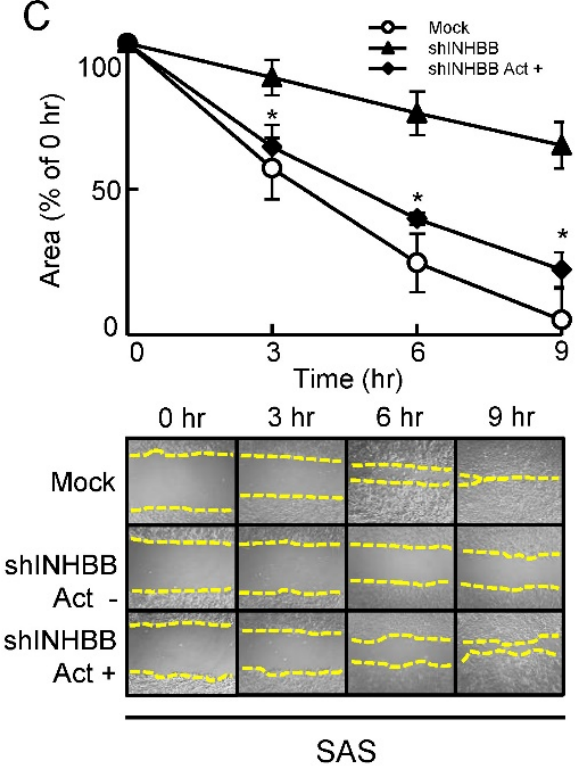

D

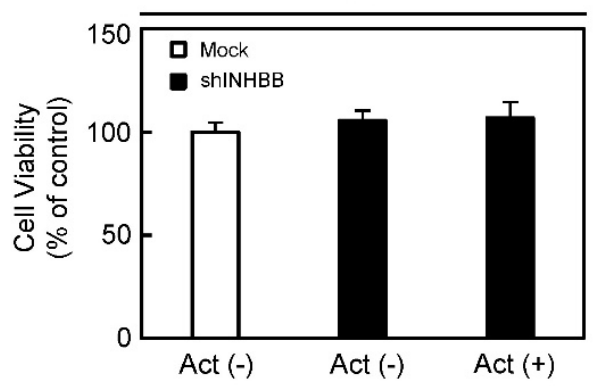

KOSC-2
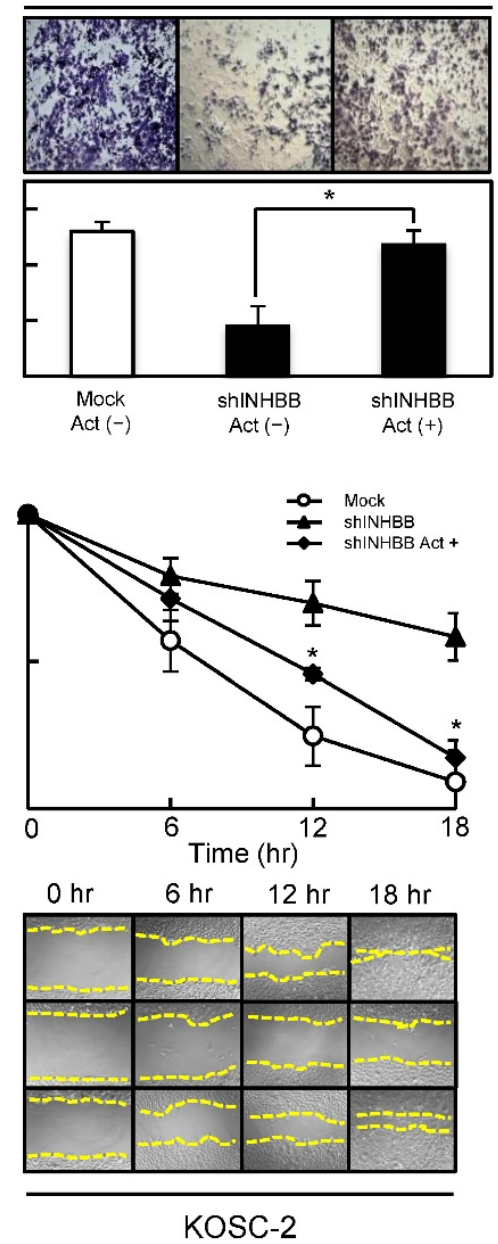

KOSC-2

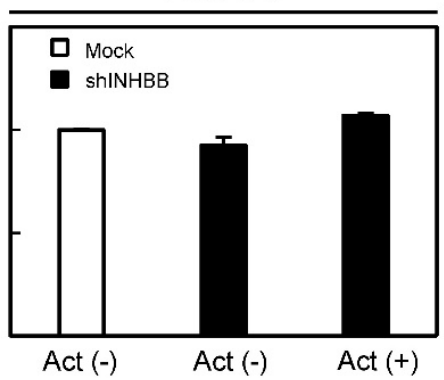

Figure 5. Functional assays after treatment with activin B. (A) Inhibition of cellular adhesion by treatment with activin B. The numbers of shINHBB cells attached to the dishes are decreased after treatment with activin B (*P < 0.05, Student's t-test). Cellular invasiveness (B) and cellular migration (C) after treatment with activin B. After treatment, invasiveness and migration of shINHBB cells are activated significantly ( $* \mathrm{P}<0.05$, Student's t-test) compared with the untreated cells. 


\section{Discussion}

The current study found that activin B (INHBB) was up-regulated in all OSCC-derived cell lines (Fig. 1). Activin B-positive OSCCs were correlated significantly with regional lymph node metastasis (Fig. 2, Table 1). Consistent with these clinical A

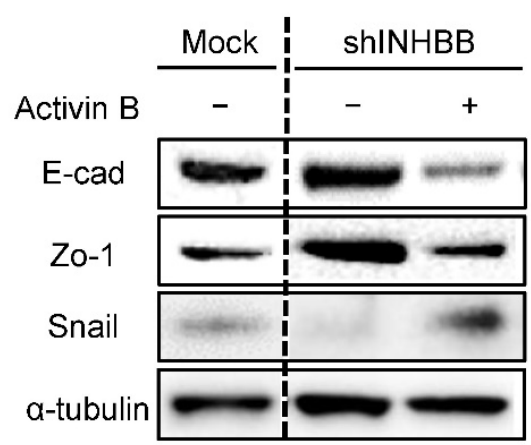

B

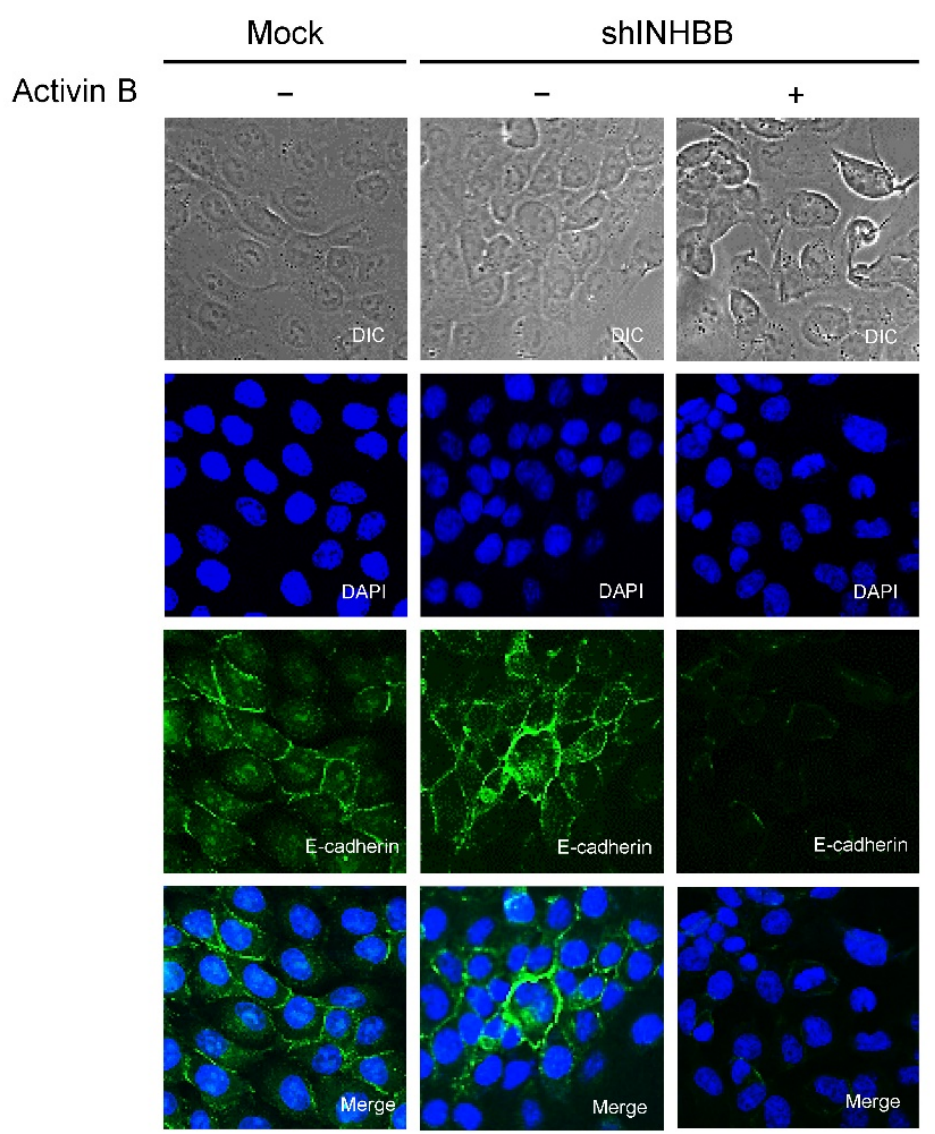

Figure 6. EMT in INHBB knockdown cells. (A) Western blotting of E-cadherin, Zo-1, and Snail proteins in shINHBB cells are treated with/without activin B. Treatment of shINHBB cells with activin B shows decreased levels of E-cad and Zo-1 and increased levels of Snail compared with the control. (B) Brightfield and immunofluorescence images of shINHBB cells are treated with/without activin B. The shINHBB cells treated with activin B shows loss of E-cadherin on the cell membrane. Scale bars: $20 \mu \mathrm{m}$ (left panels); $5 \mu \mathrm{m}$ (middle and right panels). findings, in vitro experiments showed that shINHBB cells, which have lower activin B expression, significantly inhibited tumoral metastatic activity. Activin B also promoted cellular motility and invasiveness in OSCC by controlling EMT-related gene expression.

Activin B is a prognostic biomarker and therapeutic target for renal and endometrial cancers $[14,15,40]$. In renal cancer, activin B induced tumoral invasiveness and spindle-shaped cellular morphology [40]. In endometrial cancer, activin B increased cellular migration, whereas activin B expression was not associated with survival rates [14, 15]. Therefore, up-regulated activin $\mathrm{B}$ leads to high tumoral progression in those cancers including OSCC.

The TGF- $\beta$ family, including activins, promotes EMT [41-44]. Furthermore, metastatic cancer cells are related closely to EMT, characterized by down-regulation of E-cadherin and Zo-1 [45-48], which are controlled by transcription factors, such as Snail [49-52]. We speculated that cellular behaviors associated with activin $\mathrm{B}$, such as adhesion, invasiveness, and migration, are modulated by EMT. Consistent with our hypothesis, the current data showed higher expression of E-cadherin and Zo-1 in activin B knockdown cells (Fig. 6).

In conclusion, activin B is highly expressed in OSCC and provides new insight into a highly metastatic phenotype by controlling the expression of EMTrelated genes. Further studies are needed, but the current data suggested that activin $B$ plays an important role in cellular adhesion and invasiveness in OSCC. Activin B might be a potential therapeutic target for OSCC.

\section{Abbreviations}

OSCC: oral squamous cell carcinoma; qRT-PCR: quantitative reverse transcriptase-polymerase chain reaction; IHC: immunohistochemistry; INHBB: inhibin beta b; HNOKs: human normal oral keratinocytes; shINHBB: small hairpin INHBB.

\section{Acknowledgement}

We thank Ms. Lynda C. Charters for editing this manuscript. 
Table 1. Correlation between INHBB expression and clinical classification in OSCCs.

\begin{tabular}{|c|c|c|c|c|}
\hline \multirow[t]{2}{*}{ Clinical classification } & \multicolumn{3}{|c|}{ Results of immunostaining } & \multirow[b]{2}{*}{ P value } \\
\hline & Total & INHBB negative & INHBB positive & \\
\hline \multicolumn{5}{|l|}{ Age at surgery (years) } \\
\hline$<70$ & 48 & 21 & 27 & \multirow[t]{2}{*}{0.4138} \\
\hline $70<$ & 55 & 24 & 31 & \\
\hline \multicolumn{5}{|l|}{ Gender } \\
\hline Male & 58 & 25 & 33 & \multirow[t]{2}{*}{0.1007} \\
\hline Female & 45 & 16 & 29 & \\
\hline \multicolumn{5}{|l|}{ T-primary tumor } \\
\hline $\mathrm{T} 1$ & 13 & 4 & 9 & \\
\hline $\mathrm{T} 2$ & 54 & 22 & 32 & \\
\hline T3 & 15 & 4 & 11 & \\
\hline $\mathrm{T} 4$ & 21 & 8 & 13 & \\
\hline $\mathrm{T} 1+\mathrm{T} 2$ & 67 & 28 & 39 & \multirow[t]{2}{*}{0.35900} \\
\hline $\mathrm{T} 3+\mathrm{T} 4$ & 36 & 15 & 21 & \\
\hline \multicolumn{5}{|l|}{ N-regional lymph node } \\
\hline Negative & 60 & 38 & 22 & \multirow{2}{*}{$0.00041^{*}$} \\
\hline Positive & 43 & 9 & 34 & \\
\hline \multicolumn{5}{|l|}{ Stage } \\
\hline I & 13 & 3 & 10 & \\
\hline II & 41 & 16 & 25 & \\
\hline III & 18 & 6 & 12 & \\
\hline IV & 31 & 11 & 20 & \\
\hline $\mathrm{I}+\Pi$ & 54 & 19 & 35 & \multirow[t]{2}{*}{0.4338} \\
\hline III + IV & 49 & 17 & 32 & \\
\hline \multicolumn{5}{|l|}{ Vascular invasion } \\
\hline Negative & 71 & 31 & 40 & \multirow[t]{2}{*}{0.4380} \\
\hline Positive & 32 & 14 & 18 & \\
\hline \multicolumn{5}{|l|}{ Histopathologic type } \\
\hline Well differentiated & 64 & 25 & 39 & \multirow[t]{3}{*}{0.2906} \\
\hline Moderately differentiated & 34 & 14 & 20 & \\
\hline Poorly differentiated & 5 & 2 & 3 & \\
\hline
\end{tabular}

\section{Competing Interests}

The authors declare that they have no competing interests related to this study.

\section{References}

1. Cheng A, Schmidt BL. Management of the N0 neck in oral squamous cell carcinoma. Oral and maxillofacial surgery clinics of North America. 2008; 20: 477-97.

2. Kowalski LP, Bagietto R, Lara JR, Santos RL, Silva JF, Jr., Magrin J. Prognostic significance of the distribution of neck node metastasis from oral carcinoma. Head \& neck. 2000; 22: 207-14.

3. Massano J, Regateiro FS, Januario G, Ferreira A. Oral squamous cell carcinoma: review of prognostic and predictive factors. Oral surgery, oral medicine, oral pathology, oral radiology, and endodontics. 2006; 102: 67-76.

4. Sargeran K, Murtomaa H, Safavi SM, Vehkalahti MM, Teronen O. Survival after diagnosis of cancer of the oral cavity. The British journal of oral \& maxillofacial surgery. 2008; 46: 187-91.

5. Werner S, Alzheimer C. Roles of activin in tissue repair, fibrosis, and inflammatory disease. Cytokine \& growth factor reviews. 2006; 17: 157-71.

6. Xia Y, Schneyer AL. The biology of activin: recent advances in structure, regulation and function. The Journal of endocrinology. 2009; 202: 1-12.

7. Ethier JF, Findlay JK. Roles of activin and its signal transduction mechanisms in reproductive tissues. Reproduction (Cambridge, England). 2001; 121: $667-75$

8. Hubner G, Hu Q, Smola H, Werner S. Strong induction of activin expression after injury suggests an important role of activin in wound repair. Developmental biology. 1996; 173: 490-8.

9. Munz B, Tretter YP, Hertel M, Engelhardt F, Alzheimer C, Werner S. The roles of activins in repair processes of the skin and the brain. Molecular and cellular endocrinology. 2001; 180: 169-77.

10. Basu M, Bhattacharya R, Ray U, Mukhopadhyay S, Chatterjee U, Roy SS. Invasion of ovarian cancer cells is induced byPITX2-mediated activation of TGF-beta and Activin-A. Molecular cancer. 2015:14:162.
11. Hofland J, van Weerden WM, Steenbergen J, Dits NF, Jenster G, de Jong FH. Activin A stimulates AKR1C3 expression and growth in human prostate cancer. Endocrinology. 2012; 153: 5726-34.

12. Leto $G$, Incorvaia L, Flandina $C$, Ancona $C$, Fulfaro $F$, Crescimanno $M$, et al. Clinical Impact of Cystatin C/Cathepsin L and Follistatin/Activin A Systems in Breast Cancer Progression: A Preliminary Report. Cancer investigation. 2016; 34: 415-23.

13. Loomans HA, Andl CD. Intertwining of Activin A and TGFbeta Signaling: Dual Roles in Cancer Progression and Cancer Cell Invasion. Cancers. 2014; 7: 70-91.

14. Xiong S, Klausen C, Cheng JC, Zhu H, Leung PC. Activin B induces human endometrial cancer cell adhesion, migration and invasion by up-regulating integrin beta3 via SMAD2/3 signaling. Oncotarget. 2015; 6: 31659-73.

15. Xiong S, Klausen $C$, Cheng JC, Leung PC. Activin B promotes endometrial cancer cell migration by down-regulating E-cadherin via SMAD-independent MEK-ERK1/2-SNAIL signaling. Oncotarget. 2016; 7: 40060-72.

16. Sakuma K, Kasamatsu A, Yamatoji M, Yamano Y, Fushimi K, Iyoda M, et al. Expression status of Zic family member 2 as a prognostic marker for oral squamous cell carcinoma. Journal of cancer research and clinical oncology. 2010; 136: 553-9.

17. Kasamatsu A, Uzawa $\mathrm{K}$, Nakashima D, Koike H, Shiiba M, Bukawa H, et al. Galectin-9 as a regulator of cellular adhesion in human oral squamous cell carcinoma cell lines. International journal of molecular medicine. 2005; 16: 269-73.

18. Endo $\mathrm{Y}$, Uzawa $\mathrm{K}$, Mochida $\mathrm{Y}$, Shiiba $\mathrm{M}$, Bukawa $\mathrm{H}$, Yokoe $\mathrm{H}$, et al. Sarcoendoplasmic reticulum $\mathrm{Ca}(2+)$ ATPase type 2 downregulated in human oral squamous cell carcinoma. International journal of cancer. 2004; 110: 225-31.

19. Minakawa Y, Kasamatsu A, Koike H, Higo M, Nakashima D, Kouzu Y, et al. Kinesin family member 4A: a potential predictor for progression of human oral cancer. PloS one. 2013; 8: e85951.

20. Yamatoji M, Kasamatsu A, Kouzu Y, Koike H, Sakamoto Y, Ogawara K, et al. Dermatopontin: a potential predictor for metastasis of human oral cancer. International journal of cancer. 2012; 130: 2903-11.

21. Uchida F, Uzawa K, Kasamatsu A, Takatori H, Sakamoto Y, Ogawara K, et al. Overexpression of cell cycle regulator CDCA3 promotes oral cancer progression by enhancing cell proliferation with prevention of G1 phase arrest. BMC cancer. 2012; 12: 321.

22. Unozawa M, Kasamatsu A, Higo M, Fukumoto C, Koyama T, Sakazume T, et al. Cavin-2 in oral cancer: A potential predictor for tumor progression. Molecular carcinogenesis. 2016; 55: 1037-47.

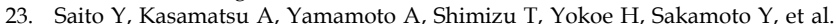
ALY as a potential contributor to metastasis in human oral squamous cell carcinoma. Journal of cancer research and clinical oncology. 2013; 139: 585-94.

24. Shimizu F, Shiiba M, Ogawara K, Kimura R, Minakawa Y, Baba T, et al. Overexpression of LIM and SH3 Protein 1 leading to accelerated G2/M phase transition contributes to enhanced tumourigenesis in oral cancer. PloS one. 2013; 8: e83187.

25. Fukumoto C, Nakashima D, Kasamatsu A, Unozawa M, Shida-Sakazume T, Higo M, et al. WWP2 is overexpressed in human oral cancer, determining tumor size and poor prognosis in patients: downregulation of WWP2 inhibits the AKT signaling and tumor growth in mice. Oncoscience. 2014; 1: 807-20.

26. Usukura K, Kasamatsu A, Okamoto A, Kouzu Y, Higo M, Koike H, et al. Tripeptidyl peptidase II in human oral squamous cell carcinoma. Journal of cancer research and clinical oncology. 2013; 139: 123-30.

27. Saito T, Kasamatsu A, Ogawara K, Miyamoto I, Saito K, Iyoda M, et al. Semaphorin7A Promotion of Tumoral Growth and Metastasis in Human Oral Cancer by Regulation of G1 Cell Cycle and Matrix Metalloproteases: Possible Contribution to Tumoral Angiogenesis. PloS one. 2015; 10: e0137923.

28. Kasama H, Sakamoto Y, Kasamatsu A, Okamoto A, Koyama T, Minakawa Y, et al. Adenosine $\mathrm{A} 2 \mathrm{~b}$ receptor promotes progression of human oral cancer. BMC cancer. 2015; 15: 563.

29. Koyama T, Ogawara K, Kasamatsu A, Okamoto A, Kasama H, Minakawa Y, et al. ANGPTL3 is a novel biomarker as it activates ERK/MAPK pathway in oral cancer. Cancer medicine. 2015; 4: 759-69.

30. Kitajima D, Kasamatsu A, Nakashima D, Miyamoto I, Kimura Y, Saito T, et al. Tie2 Regulates Tumor Metastasis of Oral Squamous Cell Carcinomas. Journal of Cancer. 2016; 7: 600-7.

31. Kimura R, Kasamatsu A, Koyama T, Fukumoto C, Kouzu Y, Higo M, et al. Glutamate acid decarboxylase 1 promotes metastasis of human oral cancer by beta-catenin translocation and MMP7 activation. BMC cancer. 2013; 13: 555.

32. Kimura Y, Kasamatsu A, Nakashima D, Yamatoji M, Minakawa Y, Koike K, et al. ARNT2 Regulates Tumoral Growth in Oral Squamous Cell Carcinoma. Journal of Cancer. 2016; 7: 702-10.

33. Gil Z, Carlson DL, Boyle JO, Kraus DH, Shah JP, Shaha AR, et al. Lymph node density is a significant predictor of outcome in patients with oral cancer. Cancer. 2009; 115: 5700-10.

34. Binmadi NO, Basile JR. Perineural invasion in oral squamous cell carcinoma: a discussion of significance and review of the literature. Oral oncology. 2011; 47: 1005-10.

35. Davis FM, Stewart TA, Thompson EW, Monteith GR. Targeting EMT in cancer: opportunities for pharmacological intervention. Trends in pharmacological sciences. 2014; 35: 479-88.

36. Kalluri R, Weinberg RA. The basics of epithelial-mesenchymal transition. The Journal of clinical investigation. 2009; 119: 1420-8. 
37. Cao Z, Livas T, Kyprianou N. Anoikis and EMT: Lethal "Liaisons" during Cancer Progression. Critical reviews in oncogenesis. 2016; 21: 155-68.

38. Lamouille $\mathrm{S}, \mathrm{Xu} \mathrm{J}$, Derynck R. Molecular mechanisms of epithelial-mesenchymal transition. Nature reviews Molecular cell biology. 2014; 15: 178-96.

39. Tam WL, Weinberg RA. The epigenetics of epithelial-mesenchymal plasticity in cancer. Nature medicine. 2013; 19: 1438-49.

40. Wacker I, Behrens J. Activin B antagonizes RhoA signaling to stimulate mesenchymal morphology and invasiveness of clear cell renal cell carcinomas. PloS one. 2014; 9: e111276.

41. Balboni AL, Cherukuri P, Ung M, DeCastro AJ, Cheng C, DiRenzo J. p53 and DeltaNp63alpha Coregulate the Transcriptional and Cellular Response to TGFbeta and BMP Signals. Molecular cancer research: MCR. 2015; 13: 732-42.

42. Rafehi S, Ramos Valdes Y, Bertrand M, McGee J, Prefontaine M, Sugimoto A, et al. TGFbeta signaling regulates epithelial-mesenchymal plasticity in ovarian cancer ascites-derived spheroids. Endocrine-related cancer. 2016; 23: 147-59.

43. Jin L, Zhu C, Wang X, Li C, Cao C, Yuan J, et al. Urocortin attenuates TGFbeta1-induced Snail1 and slug expressions: inhibitory role of Smad7 in Smad2/3 signaling in breast cancer cells. Journal of cellular biochemistry. 2015; 116: 2494-503.

44. Murakami M, Suzuki M, Nishino Y, Funaba M. Regulatory expression of genes related to metastasis by TGF-beta and activin A in B16 murine melanoma cells. Molecular biology reports. 2010; 37: 1279-86.

45. Tsai JH, Yang J. Epithelial-mesenchymal plasticity in carcinoma metastasis. Genes \& development. 2013; 27: 2192-206.

46. Canesin G, Cuevas EP, Santos V, Lopez-Menendez C, Moreno-Bueno G, Huang Y, et al. Lysyl oxidase-like 2 (LOXL2) and E47 EMT factor: novel partners in E-cadherin repression and early metastasis colonization. Oncogene. 2015; 34: 951-64.

47. Zhao JL, Liang SQ, Fu W, Zhu BK, Li SZ, Han H, et al. The LIM domain protein FHL1C interacts with tight junction protein ZO-1 contributing to the epithelial-mesenchymal transition (EMT) of a breast adenocarcinoma cell line. Gene. 2014; 542: 182-9.

48. Tomei P, Masola V, Granata S, Bellin G, Carratu P, Ficial M, et al. Everolimus-induced epithelial to mesenchymal transition (EMT) in bronchial/pulmonary cells: when the dosage does matter in transplantation. Journal of nephrology. 2016; 29: 881-91.

49. Papiewska-Pajak I, Kowalska MA, Boncela J. Expression and activity of SNAIL transcription factor during Epithelial to Mesenchymal Transition (EMT) in cancer progression. Postepy higieny i medycyny doswiadczalnej (Online). 2016; 70: 968-80.

50. Bonavida B, Baritaki S. Inhibition of Epithelial-to-Mesenchymal Transition (EMT) in Cancer by Nitric Oxide: Pivotal Roles of Nitrosylation of NF-kappaB, YY1 and Snail. Forum on immunopathological diseases and therapeutics. 2012; 3: 125-33.

51. Zhang X, Zhang T, Yang K, Zhang M, Wang K. miR-486-5p suppresses prostate cancer metastasis by targeting Snail and regulating epithelial-mesenchymal transition. OncoTargets and therapy. 2016; 9: 6909-14.

52. Castro Alves C, Rosivatz E, Schott C, Hollweck R, Becker I, Sarbia M, et al. Slug is overexpressed in gastric carcinomas and may act synergistically with SIP1 and Snail in the down-regulation of E-cadherin. The Journal of pathology. 2007; 211: 507-15. 